\title{
Proxy indicators of sand temperature help project impacts of global warming on sea turtles in northern Australia
}

\author{
M. M. P. B. Fuentes ${ }^{1, *}$, J. A. Maynard ${ }^{2,3}$, M. Guinea ${ }^{4}$, I. P. Bell ${ }^{5}$, \\ P. J. Werdell ${ }^{6}$, M. Hamann ${ }^{1}$ \\ ${ }^{1}$ School of Earth and Environmental Sciences, James Cook University, Townsville, Queensland 4811, Australia \\ ${ }^{2}$ Applied Environmental Decision Analysis CERF Hub, School of Botany, University of Melbourne, \\ Parkville, Victoria 3010, Australia \\ ${ }^{3}$ Climate Change Group, Great Barrier Reef Marine Park Authority, PO Box 1379, 2-68 Flinders St., \\ Townsville, Queensland 4810, Australia \\ ${ }^{4}$ School of Science and Primary Industries, Faculty of Education, Health and Science, \\ Charles Darwin University, Darwin, Northern Territory 0909, Australia \\ ${ }^{5}$ Threatened Species Branch, Environmental Protection Agency, Townsville, Queensland 4810, Australia \\ ${ }^{6}$ Science Systems and Applications Inc., NASA Goddard Space Flight Center, Greenbelt, Maryland 20771, USA
}

\begin{abstract}
Global warming poses serious threats to sea turtle populations since sex determination and hatching success are dependent on nest temperature. Nest sex ratios may be skewed towards a predominantly female output, and eggs may be consistently exposed to temperatures that exceed thermal mortality thresholds. Consequently, understanding the rates at which sand temperatures are likely to change represents an immediate priority. Here, we use regression analyses to correlate air temperature (AT) and high-resolution sea surface temperature (SST) to sand temperature at 5 rookeries in northern Australia. We show that previous studies using only AT could potentially be improved by including SST as a covariate. At our study sites, combined SST and AT models explained between 79 and $94 \%$ of the variance in sand temperature in recent years. Our results suggest that hatchling production will skew towards all females at 3 of our sites by 2070 (Moulter Cay, Milman Island and Bramble Cay) and by as early as 2030 at Ashmore Island and Bare Sand Island. The projections presented here can inform the timely and targeted implementation of local-scale management strategies to reduce the impacts of global warming on sea turtle populations. Identifying and testing new strategies deserves immediate attention, as does further research into the adaptive capacity of sea turtles.
\end{abstract}

KEY WORDS: Global warming · Temperature · Sea turtles · Sex ratio · Hatching success Torres Strait · Australia

\section{INTRODUCTION}

Successful sea turtle egg incubation only occurs within a narrow thermal range of 25 to $33^{\circ} \mathrm{C}$ (Miller 1985, Spotila \& Standora 1985). Incubation near the higher thermal threshold results in high occurrence of scale and morphological abnormalities, and prolonged exposure above $33^{\circ} \mathrm{C}$ typically results in hatchling mortality (Packard et al. 1977, Miller 1985). Also, sex determination in sea turtles is temperature-dependent with a 50:50 male:female sex ratio produced in eggs exposed to a pivotal temperature (PT) of $\sim 29^{\circ} \mathrm{C}$ (differs slightly within and between species) (Standora \& Spotila 1985, Mrosovsky 1994, Ackerman 1997). Eggs exposed to temperatures above the PT yield female hatchlings, while eggs kept below the PT yield males 
(Davenport 1997). The transitional range of temperature (TRT) is the range of temperature in which sex ratio shifts from all male to all female; the proportion of males produced depends in part on the steepness of the TRT curve (Mrosovsky \& Pieau 1991, Davenport 1997). Since the early life history of sea turtles is so closely tied to temperature, global warming poses a serious threat to their populations. The impacts are likely to manifest themselves in 2 key ways: a skewing of gender ratios in nests towards most or even all females (Mrosovsky 1994, Hawkes et al. 2007), and increased incidences of scale and morphological abnormalities as well as an increase in hatchling mortality rates (Hawkes et al. 2007).

Given the seriousness of the global warming threat, it is critical to understand the rate at which sand temperatures are likely to change and the extent to which associated changes in hatching success and sex ratio will vary spatially as climate change progresses. Such information could allow for the implementation of management strategies, at least at the local scale, to reduce sand temperatures at key rookeries. Predicting changes in sand temperature in space and time is challenging, as the relative importance of the large number of variables that influence sand temperature are not well understood.

Variables that influence sand temperature include: air temperature (AT), sea surface temperature (SST), wind speed, solar radiation, local vegetation types, beach aspect angle and sand characteristics such as albedo, heat capacity, density, solar radiation absorption and emission and convective heat transfer (Mrosovsky et al. 1984, Godfrey et al. 1996, Hays et al. 1999, 2001). All of these variables vary spatially and temporally, and of them only AT and SST can be monitored in near real-time, as data from weather stations and environmental monitoring satellites are readily available. Previous studies have related AT to sand temperature and have found the two to be correlated strongly enough to predict and reconstruct sand temperature at rookeries in Ascension Island, Pasture Bay (Long Island, Antigua), Thomson Causeway (Mississippi, USA) and Bald Head Island (North Carolina, USA) (see Janzen 1994, Hays et al. 1999, 2003, Glen \& Mrosovsky 2004, Hawkes et al. 2007).

For many sea turtle rookeries, such as those in northeast Australia and the Torres Strait, remote and in situ data on AT are usually unavailable. In such cases, previous studies have used data from weather stations that are located closest to the rookeries, potentially reducing the validity and applicability of the projections made, even if only slightly (e.g. Hays et al. 1999, Godley et al. 2001). In contrast, high-resolution $(\sim 1 \mathrm{~km})$ SST data, calibrated to ship-based sensors and drift buoys, are available worldwide from polar orbiting satellites. Also, unlike AT over the oceans, projections of SST are readily available for a range of emissions scenarios put forward by the Intergovernmental Panel on Climate Change (IPCC 2007). Here, we test: (1) the extent to which SST can be used as a proxy indicator of sand temperature and (2) its proficiency as a predictor of sand temperature against in situ measurements of AT. We then use the relationship between a combined AT and SST model and sand temperature to project nest temperatures at 5 key northern Australian rookeries and hence improve our understanding of the likely impacts of global warming on sea turtles in the region. The results are discussed in light of the adaptive capacity of sea turtles as well as options currently available to resource managers.

\section{MATERIALS AND METHODS}

Temperature data. Sand temperature was recorded at Ashmore, Bare Sand and Milman Islands from December 2006 to January 2008, at Moulter Cay from November 2007 to May 2008 and at Bramble Cay from April to December 2007 (Fig. 1). The sampling period encompasses the nesting period and embryonic development for sea turtles at each rookery. The rookeries studied provide nesting grounds for 4 sea turtle species: green Chelonia mydas, hawksbill Eretmochelys imbricata, flatback Natator depressus

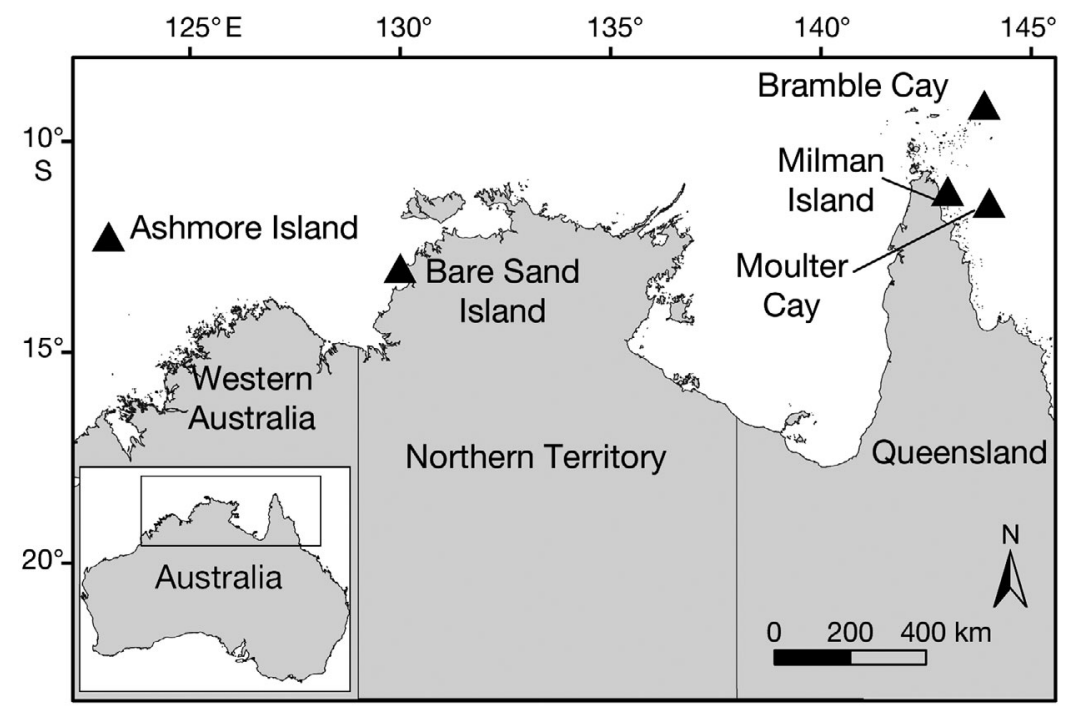

Fig. 1. Location of study sites ( $\mathbf{\Delta})$ along the northern coast of Australia 
and olive ridley Lepidochelys olivacea. Data loggers were located in representative nesting areas and were deployed at open areas without vegetation. As hawksbill turtles nest mainly in vegetated areas (Dobbs et al. 1999) the temperature recorded at Milman Island is more representative of the incubating environment for green turtles or hawksbills, which nest in unvegetated areas. Measurements were made at a standard depth of $50 \mathrm{~cm}$ (as per Spotila et al. 1987, Matsuzawa et al. 2002). Data were collected using I buttons (Thermodata, Alpha-Mach), Tinytag TK-4014 data loggers (Hasting Data Loggers) and Tinytag Water Temp Pro. All data loggers were calibrated against a mercury thermometer and have an accuracy of $\pm 0.1^{\circ} \mathrm{C}$.

AT data for Milman Island, Moulter Cay and Bramble Cay were obtained from calibrated Tinytag TK4014 data loggers deployed according to requirements by the Australian Bureau of Meteorology (see Canteford 1997). AT for Ashmore and Bare Sand Islands was obtained from the International Comprehensive Ocean Atmosphere Data Sets (ICOADS; (http://icoads.noaa. gov/coads). ICOADS is an extensive dataset which providesAT, SST, relative humidity, cloudiness, sea level pressure and wind information for all oceans of the world back to 1854 and has been used by similar studies (e.g. Hays et al. 2003, McMahon \& Hays 2006). AT data from ICOADS were only used for months where more than 10 observations were recorded (as in Hays et al. 2003).

SST was obtained from the NASA Moderate Resolution Imaging Spectroradiometer (MODIS) onboard the Aqua spacecraft. Approximately 2900 spatially extracted MODIS-Aqua Level-2 SST files containing all or part of each rookery were acquired from the NASA Ocean Biology Processing Group (McClain et al. 2006). Only the nighttime series was used, which contains $11 \mu \mathrm{m}$ (thermal infrared) SST measurements (Minnett et al. 2004) made from February 2005 to February 2008 at a spatial resolution of $\sim 1 \mathrm{~km}^{2}$. Quality-control metrics were applied to the SST retrievals and only pixels with a quality level $\leq 2$ were retained (on a scale of 0 to 4 , with 4 being completely unusable), thereby eliminating measurements with extreme viewing geometries (>75 degrees), with high degrees of spatial inhomogeneity or outside physically realistic ranges of $\mathrm{SST}$ (e.g. $<-2^{\circ} \mathrm{C}$ or $>45^{\circ} \mathrm{C}$ ). For each satellite file, the mean of all remaining pixels within a $3 \times 3$ pixel box centred on each in situ target, i.e. a rookery, was recorded. Data gaps were back-filled unless more than $7 \mathrm{~d}$ long (see Maynard et al. 2008) and monthly average temperatures were used in regression analyses.

Analysis. Regression analyses were used to determine the relationship between mean monthly sand temperature at our study sites and mean monthly SST and AT. Three linear regression models were used to predict sand temperature: (1) SST only, (2) AT only and (3) SST and AT. The fit of these 3 models were compared using Akaike's information criterion (AIC). AIC is a model selection tool that quantifies the relative goodness-of-fit of various previously derived statistical models (Hurvich \& Tsai 1989, Burnham \& Anderson 2004). A corrected AIC ( $\mathrm{AIC}_{\mathrm{C}}$ ) was used in the present study, as suggested by Burnham \& Anderson (2004), since our sample size was small ( $\mathrm{n}<40$ ) (as used in Johnson \& Omland 2004, Cinner et al. 2009). Since individual AIC values are affected by sample size, $\mathrm{AIC}_{\mathrm{C}}$ values were rescaled using the following equation:

$$
\Delta_{i}=\mathrm{AIC}_{i}-\mathrm{AIC}_{\text {min }}
$$

where $\Delta_{i}$ represents the loss of information from using model $i$ instead of the best fit model (best model has $\Delta_{i}=0$ ) and $\mathrm{AIC}_{\min }$ is the minimum of the different $\mathrm{AIC}_{i}$ values (Burnham \& Anderson 2004). Support for each model is thus quantified based on these $\Delta_{i}$ values, where models with values $\leq 2$ have substantial support, values between 4 and 7 indicate some support and values $>10$ no support (Burnham \& Anderson 2004). The $\mathrm{AIC}_{\mathrm{c}}$ weight $\left(w_{i}\right)$ - which reflects the relative likelihood of each model being the best fitting model among those considered - was also calculated for each model (Burnham \& Anderson 2004).

After the best model was selected for each rookery, sand temperatures for 2030 and 2070 were predicted based on 'conservative' (B1 emissions scenario, IPCC 2007) and 'extreme' (A1T emissions scenario, IPCC 2007) AT and SST projected by the Commonwealth Scientific and Industrial Research Organization in Australia (CSIRO and Australian Bureau of Meteorology 2007, IPCC 2007; Table 1). We assumed that sand temperatures $\geq 29^{\circ} \mathrm{C}$ resulted in all female hatchlings and that the proportion of females increased linearly between 26 and $29^{\circ} \mathrm{C}$ (as per Miller \& Limpus 1981, Booth \& Astill 2001).

Table 1. Projected regional increases in sea surface (SST), and air (AT) temperatures, under conservative (based on B1 emissions scenario, IPCC 2007) and extreme (based on A1T emissions scenario, IPCC 2007) scenarios (CSIRO \& Australian Bureau of Meteorology 2007)

\begin{tabular}{|clcc|}
\hline Year & Scenario & $\begin{array}{r}\text { Projected increase } \\
\text { in SST }\left({ }^{\circ} \mathrm{C}\right)\end{array}$ & $\begin{array}{c}\text { Projected increase } \\
\text { in AT }\left({ }^{\circ} \mathrm{C}\right)\end{array}$ \\
\hline 2030 & Conservative & 0.3 & 0.7 \\
& Extreme & 0.6 & 1.2 \\
2070 & Conservative & 1.2 & 1.8 \\
& Extreme & 1.5 & 3.4 \\
\hline
\end{tabular}




\section{RESULTS}

\section{Regression analyses}

Both SST and AT were strongly correlated with sand temperature at our study sites, during the survey years (Fig. 2). AT was more strongly correlated with sand temperature at Milman Island, Moulter Cay and Bramble Cay. In contrast, SST was more strongly correlated with sand temperature at Ashmore and Bare Sand Islands (Fig. 2, Table 2). Both SST and AT independently explained more than $50 \%\left(\mathrm{r}^{2}>0.5\right)$ of the variability in sand temperature at all sites except in the case of SST at Milman Island $\left(\mathrm{r}^{2}=0.39\right.$, see Table 2$)$. The strongest correlations were between AT and sand temperature at Moulter Cay and between SST and sand temperature at Ashmore Island $\left(\mathrm{r}^{2}=0.90\right.$ in both cases).
As the $\Delta_{i}$ values were $<2$ for more than one model at each site (Table 2), there was no substantial support for a 'best' model. However, the $\mathrm{AIC}_{\mathrm{c}}, w_{i}$ and $\mathrm{r}^{2}$ values indicated that the model that best describes sand temperature at all rookeries, except Bare Sand Island, is a combination of SST and AT (Table 2). At Bare Sand Island, including AT in the model did not improve the capacity of SST to predict sand temperature at that site. Notably, in all cases the combined SST/AT models explained at least $79 \%$ of the variability in sand temperature observed during the study years.

\section{Sand temperature projection}

The combined SST/AT model was used to predict sand temperature - for 2030 and 2070 - for all rookeries except Bare Sand Island, where the SST model
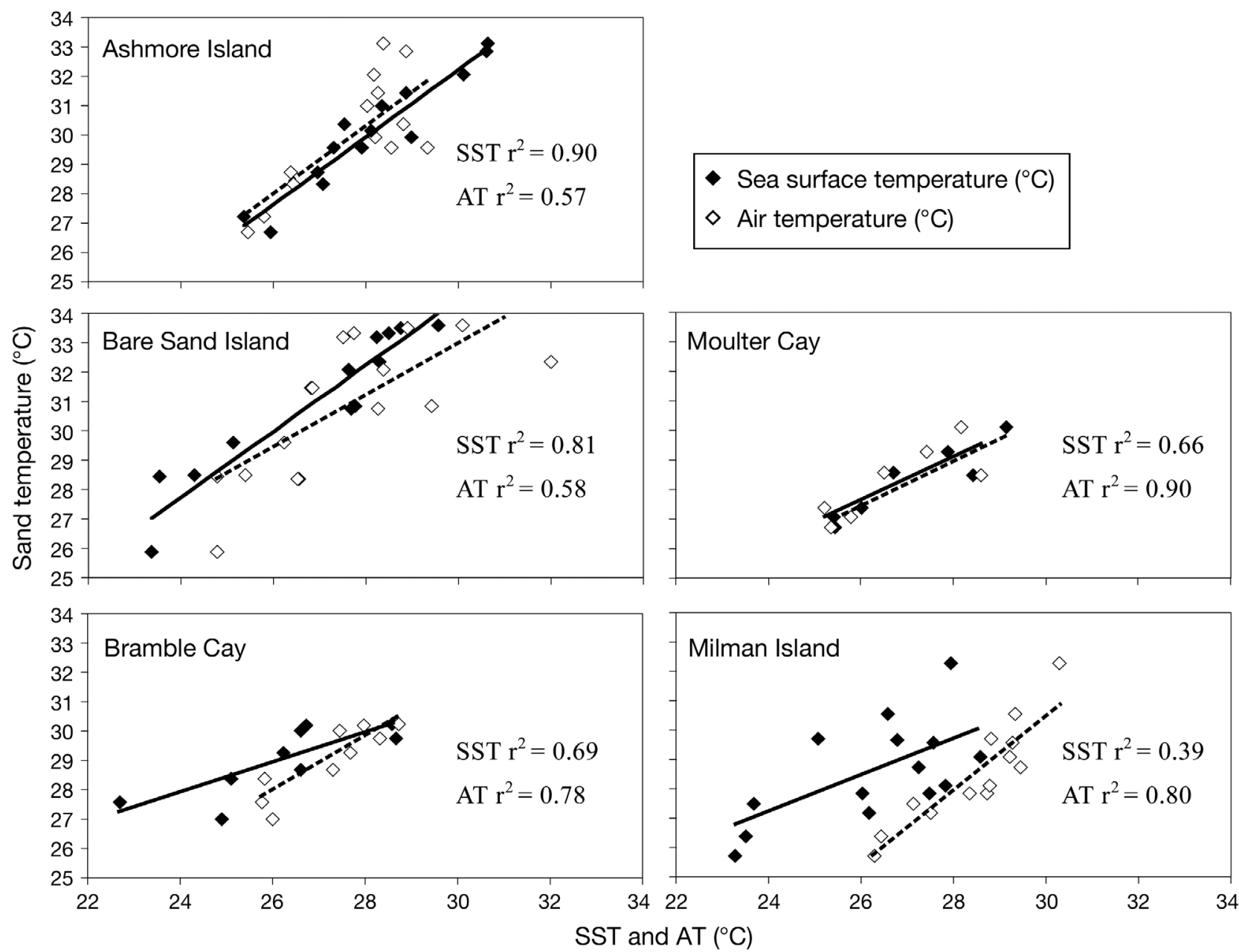

Fig. 2. Relationship between mean monthly sea surface temperature (SST)/air temperature (AT) and sand temperature at each study site. Linear fits to regressions for SST and AT are represented by solid and dashed lines, respectively 
Table 2. Comparison of candidate models to describe sand temperature at each rookery. Models with the best fit (lowest corrected Akaike's information criterion $\left[\mathrm{AIC}_{\mathrm{C}}\right]$ values and highest $\mathrm{AIC}_{\mathrm{c}}$ weight $\left[w_{i}\right]$ ) are in bold. n: no. of months for which temperatures are available; SST: sea surface temperature; AT: air temperature

\begin{tabular}{|lcccccc|}
\hline Site & $\mathrm{n}$ & Variable & $\mathrm{r}^{2}$ & $\mathrm{AIC}_{\mathrm{c}}$ & $\Delta_{i}$ & $W_{i}(\%)$ \\
\hline Moulter Cay & 7 & SST+AT & $\mathbf{0 . 9 4}$ & $\mathbf{4 . 0 0}$ & 0 & $\mathbf{7 1 . 6 4}$ \\
& 7 & SST & 0.66 & 9.87 & 5.87 & 0.06 \\
\multirow{4}{*}{ Ashmore Island } & 7 & AT & 0.90 & 4.77 & 0.77 & 28.30 \\
& 14 & SST+AT & $\mathbf{0 . 9 3}$ & $\mathbf{2 . 5 2}$ & 0 & $\mathbf{5 2 . 5 6}$ \\
& 14 & SST & 0.90 & 2.67 & 0.15 & 43.59 \\
Milman Island & 14 & AT & 0.57 & 4.70 & 2.18 & 3.84 \\
& 14 & SST+AT & $\mathbf{0 . 8 9}$ & $\mathbf{2 . 5 8}$ & 0 & $\mathbf{5 9 . 6 9}$ \\
Bare Sand Island & 14 & SST & 0.39 & 4.35 & 1.76 & 7.15 \\
& 14 & AT & 0.80 & 3.07 & 0.49 & 33.16 \\
& 14 & SST+AT & 0.81 & 4.05 & 0.15 & 39.12 \\
Bramble Cay & 14 & SST & $\mathbf{0 . 8 1}$ & $\mathbf{3 . 9 0}$ & 0 & $\mathbf{4 6 . 9 6}$ \\
& 14 & AT & 0.58 & 4.91 & 1.01 & 13.92 \\
& 9 & SST+AT & $\mathbf{0 . 7 9}$ & $\mathbf{3 . 1 2}$ & 0 & $\mathbf{4 3 . 1 9}$ \\
& 9 & SST & 0.69 & 3.55 & 0.43 & 25.74 \\
& 9 & AT & 0.78 & 3.39 & 0.27 & 31.08 \\
\hline
\end{tabular}

Table 3. Models used to predict sand temperature for 2030 and 2070 for each rookery. SST: sea surface temperature; AT: air temperature

\begin{tabular}{|ll|}
\hline Site & Model \\
\hline Moulter Cay & Sand temperature $=[($ SST $\times-0.236)+($ AT $\times 1.022)+6.915]$ \\
Ashmore Island & Sand temperature $=[($ SST $\times 0.984)+($ AT $\times 0.299)-5.911]$ \\
Milman Island & Sand temperature $=[($ SST $\times-0.578)+($ AT $\times 2.032)-14.119]$ \\
Bare Sand Island & Sand temperature $=[($ SST $\times 1.1231)+0.8104]$ \\
Bramble Cay & Sand temperature $=[($ SST $\times-0.029)+($ AT $\times 0.991)+2.786]$ \\
\hline
\end{tabular}

SST/AT for the remaining islands) provide improved model prediction and increased statistical confidence when compared to the other models.

The projections generated indicate that average sand temperature across all the rookeries will increase between 0.57 and $5.68^{\circ} \mathrm{C}$ by 2030 (depending on the emissions scenario used) and between 1.05 and $6.69^{\circ} \mathrm{C}$ by 2070 during the nesting season, with Bare Sand Island experiencing the highest increases in mean sand temperature (Table 4). Milman Island will also experience high increases in mean sand temperature $\left(1.0\right.$ to $1.8^{\circ} \mathrm{C}$ by 2030 and 2.67 to $5.74^{\circ} \mathrm{C}$ by 2070). However, Milman Island currently has a low mean sand temperature relative to the other study rookeries $\left(27.8^{\circ} \mathrm{C}\right)$, so the projected increase will not have as dramatic an effect on hatching success and gender ratios as at other rookeries. Projections suggest that sand temperatures at Ashmore Island and Bare Sand Island will almost never produce males by 2030 and may even regularly reach the upper thermal incubating threshold of $33^{\circ} \mathrm{C}$ (Table 4). By 2070, eggs at these 2 sites will regularly incubate at was used, as this model best described the sand temperature at this site. For a description of models used see Table 3.

Since there was no significant difference between the $\mathrm{Aic}_{\mathrm{C}}$ values and no clear best model, and only an indication of the model that best describes sand temperature, a 2-tailed pairedsample $t$-test was conducted between the generated sand temperature from all 3 different models for all sites to investigate whether the selected models improved our projections. The significant difference between the predicted sand temperatures when using different models (2-tailed paired-sample $t$ test: Moulter Cay, all p < 0.005, df =11; Ashmore Island, all $\mathrm{p}<0.008, \mathrm{df}=11$; Milman Island, all $\mathrm{p}<0.009$, df $=11$; Bramble Cay, all p < 0.007, df = 11) under both climate change scenarios and years - indicates that the models selected (SST for Bare Sand Island and
Table 4. Projected sand temperature during nesting season (November to March) at each rookery under conservative and extreme climate change scenarios for 2030 and 2070

\begin{tabular}{|c|c|c|c|c|}
\hline Site & Year & Scenario & $\begin{array}{l}\text { Projected increase } \\
\text { in sand } \\
\text { temperature }\left({ }^{\circ} \mathrm{C}\right)\end{array}$ & $\begin{array}{c}\text { Mean sand } \\
\text { temperature }\left({ }^{\circ} \mathrm{C}\right) \\
\text { during nesting season }\end{array}$ \\
\hline $\begin{array}{l}\text { Moulter } \\
\text { Cay }\end{array}$ & $\begin{array}{l}2030 \\
2070\end{array}$ & $\begin{array}{l}\text { Conservative } \\
\text { Extreme } \\
\text { Conservative } \\
\text { Extreme }\end{array}$ & $\begin{array}{l}0.6 \\
1.1 \\
1.6 \\
3.1\end{array}$ & $\begin{array}{l}29.7 \pm 0.17 \\
30.2 \pm 0.17 \\
30.7 \pm 0.20 \\
32.2 \pm 0.20\end{array}$ \\
\hline $\begin{array}{l}\text { Ashmore } \\
\text { Island }\end{array}$ & $\begin{array}{l}2030 \\
2070\end{array}$ & $\begin{array}{l}\text { Conservative } \\
\text { Extreme } \\
\text { Conservative } \\
\text { Extreme }\end{array}$ & $\begin{array}{l}0.8 \\
1.2 \\
2.0 \\
2.8\end{array}$ & $\begin{array}{l}32.8 \pm 0.30 \\
33.3 \pm 0.37 \\
33.9 \pm 0.25 \\
34.7 \pm 0.27\end{array}$ \\
\hline $\begin{array}{l}\text { Milman } \\
\text { Island }\end{array}$ & $\begin{array}{l}2030 \\
2070\end{array}$ & $\begin{array}{l}\text { Conservative } \\
\text { Extreme } \\
\text { Conservative } \\
\text { Extreme }\end{array}$ & $\begin{array}{c}1.0 \\
1.8 \\
2.67 \\
5.74\end{array}$ & $\begin{array}{c}28.8 \pm 0.31 \\
29.6 \pm 0.31 \\
30.47 \pm 0.32 \\
33.54 \pm 0.32\end{array}$ \\
\hline $\begin{array}{l}\text { Bare Sand } \\
\text { Island }\end{array}$ & $\begin{array}{l}2030 \\
2070\end{array}$ & $\begin{array}{l}\text { Conservative } \\
\text { Extreme } \\
\text { Conservative } \\
\text { Extreme }\end{array}$ & $\begin{array}{l}5.34 \\
5.68 \\
6.35 \\
6.69\end{array}$ & $\begin{array}{l}34.65 \pm 0.32 \\
34.99 \pm 0.32 \\
35.66 \pm 0.30 \\
36.00 \pm 0.30\end{array}$ \\
\hline $\begin{array}{c}\text { Bramble } \\
\text { Cay }\end{array}$ & $\begin{array}{l}2030 \\
2070\end{array}$ & $\begin{array}{l}\text { Conservative } \\
\text { Extreme } \\
\text { Conservative } \\
\text { Extreme }\end{array}$ & $\begin{array}{l}0.57 \\
1.05 \\
1.77 \\
3.34\end{array}$ & $\begin{array}{l}30.45 \pm 0.21 \\
30.93 \pm 0.21 \\
31.65 \pm 0.30 \\
33.22 \pm 0.30\end{array}$ \\
\hline
\end{tabular}


temperatures above those known to cause deformed hatchlings and severe mortality (Table 4). Projections suggest that Moulter Cay, Milman Island and Bramble Cay will experience sand temperatures that produce mainly female hatchlings by 2070 .

\section{DISCUSSION}

For study sites in northern Australia and Torres Strait, a combined SST/AT model best predicts sand temperature. Indeed, spatial variation in the capacity of AT and SST to predict sand temperature at our sites was high enough to suggest that the efficiency of combined models should at least be explored for other locations. Previous studies that have only included AT (e.g. Hays et al. 1999, 2003, Hawkes et al. 2007) would likely have benefited, with respect to the accuracy of projections, from the incorporation of high resolution SST data. Certainly a structured selection process - to decide which meteorological variables to incorporate in projecting models-would aid the selection of the best fitting model for a particular rookery. If such a process is undertaken, projections made will be as accurate as possible and, therefore, best assess the likely impacts of global warming on sea turtle populations.

Most importantly, information provided by the regression models generated here suggests that, without adaptation, there will be a bleak future for the sea turtle populations of northern Australia. Our models predict that, by 2030, sand temperature at Moulter Cay, Ashmore Island and Bramble Cay will have increased to a point that will ensure the majority of eggs incubate well above the pivotal temperature, resulting in a near complete feminization of annual hatchling output. Projections are more severe for Bare Sand Island, where sand temperature is likely to regularly reach the upper thermal incubating threshold of $33^{\circ} \mathrm{C}$, causing mortality of eggs. By 2070 , assuming no other substantial changes to local conditions occurs, it is predicted that eggs at Moulter Cay, Milman Island and Bramble Cay will incubate at temperatures near the higher thermal threshold, resulting in hatchlings with a higher incidence of scale and morphological abnormalities. Eggs at Ashmore Island and Bare Sand Island will consistently incubate at temperatures above the higher thermal threshold, causing mortality and a major reduction in hatching success at these rookeries. In contrast, Milman Island is predicted to keep producing males through 2030. Similar results to those presented here are predicted for Cape Canaveral and Bald Head Island, North Carolina, USA, where a feminization of the loggerhead Caretta caretta population and an increase in the production of female hatchlings is expected, respectively, with an increase of $2{ }^{\circ} \mathrm{C}$ (Hawkes et al. 2007). All projections presented here are likely to be underestimates, since metabolic heating will increase sand temperature by approximately $0.5^{\circ} \mathrm{C}$ (see Booth \& Astill 2001) during the middle third of the nest incubation period. Additionally, the projections presented here are likely to vary slightly since the models used did not account for variation in nest depth or nests laid in shaded or vegetated areas.

On a more positive note, there are a number of ways that populations with temperature-dependent sex determination (TSD), such as sea turtles, could adapt in response to global warming. Potential adaptive responses include: (1) changes in nest-site choice and distribution of nesting grounds (Hays et al. 2001); (2) in situ adaption by adjusting either the pivotal temperature for sex determination (Davenport 1989, Hawkes et al. 2007) or the maximum incubating threshold tolerance; and (3) shifting nesting to cooler months (Hays et al. 2003, Weishampel et al. 2004, Pike et al. 2006). However, quantitative genetic analysis and behavioural data suggest that species with TSD may not be able to evolve fast enough to counter the negative effects of global warming (Janzen 1994). Unfortunately, the majority of studies that investigate the likelihood of adaptive responses offsetting impacts of climate change have been conducted with freshwater turtles and not sea turtles (e.g. Morjan 2003, Schwanz \& Janzen 2008). However, it is hypothesized that their conclusions can be applied generally to other organisms with TSD, including sea turtles (Janzen 1994, Schwanz \& Janzen 2008). Throughout the millions of years that sea turtles have existed they have demonstrated a biological capacity to adapt to climate change. Sea turtles have persisted through dramatic changes in climate (temperature and sea level rise) (Hamann et al. 2007, Hawkes et al. 2009) and adapted by redistributing their nesting sites and developing new migratory routes (Hamann et al. 2007). Clearly, investigating the extent to which different sea turtle species can or will exhibit any of the adaptive responses described here and determining whether the responses can counteract predicted impacts of global warming represent fruitful areas of future research.

As there is the possibility that adaptation by sea turtles will be slow and not sufficient to offset the impact of global warming, implementing short-term management strategies that mitigate impacts will be necessary. Such strategies are critical, given the rapid rates of temperature increase and environmental change projected by the Intergovernmental Panel on Climate Change (IPCC 2007). Foreseeable strategies which could be implemented by resource managers include using natural and/or artificial materials to shade 
beaches at key rookeries, relocating nests to more suitable incubation sites and sprinkling nests with cool water (Naro-Maciel et al. 1999, Hamann et al. 2007). Implementing any of these strategies, even at small spatial scales, could be cost- and time-intensive, which will vary the extent to which such solutions are realistic in developed and developing nations. Given the severe implications of the projections presented here, the realities of implementing each strategy type at a rookery rather than population scale warrant further research. As researchers and managers test strategies, it seems likely there will be substantial benefits to information sharing through workshops and in the preparation of general guidelines that help managers to reduce any negative side effects associated with strategies.

Timely and targeted implementation of strategies that work to mitigate the impacts of global warming on sea turtle populations is going to require an understanding of spatial variability in impact severity. This information can be obtained by broadly applying predictive models like those used here. The combined SST/AT model improved our capacity to project future nesting conditions in northern Australia and Torres Strait and may improve the accuracy of projections made in other regions. Since sand temperature is dependent on the interaction of many variables, including numerous descriptors of the sand itself, there is still room for improvement of the models tested here by incorporating other variables, such as sand colour and beach facing direction. An example of this is the novel approach by Mitchell et al. (2008), who developed a mechanistic model that shows how climate, soil and topography interact with physiology and nesting behaviour to determine sex ratios. Their work focussed on the tuatara, an endemic lizard-like reptile from New Zealand.

In conclusion, our results suggest that it is highly likely that incorporating SST will improve the accuracy of models used to project sand temperature and resultant impacts on sea turtle populations. If the projected increases in temperature presented here eventuate, then global warming will seriously impact the population size and geographic range of sea turtles in northern Australia. Therefore, more research into the adaptive capacity of these endangered reptiles is critical. Importantly, strategies which document, better understand and even mitigate the impacts of global warming need to be tested at the rookery scale, and those that are successful should be made available as guidelines to managers worldwide.

Acknowledgements. This work was supported and funded by the Australian Government's Marine and Tropical Scientific Research Facility, Great Barrier Reef Marine Park Authority,
National Geographic, the PADI Foundation and the Queensland Environmental Protection Agency, including Queensland Parks and Wildlife (QPW), Torres Strait Regional Authority. We thank the traditional owners of Bramble Cay for allowing access and granting permission to work on their land. Field work complies with the current laws of Australia, and all permits necessary for the project were obtained (QPW permit no. WISPO4316207).

\section{LITERATURE CITED}

Ackerman RA (1997) The nest environment and the embryonic development of sea turtles. In: Lutz PL, Musick JA (eds) The biology of sea turtles. CRC Press, Boca Raton, FL, p 83-107

Booth DT, Astill K (2001) Temperature variation within and between nests of the green sea turtle, Chelonia mydas on Heron Island, Great Barrier Reef. Aust J Zool 49:71-84

Burnham KP, Anderson DR (2004) Multimodel inference: understanding AIC and BIC in model selection. Sociol Methods Res 33:261-304

Canteford R (1997) Guidelines for the siting and exposure of meteorological instruments and observing facilities. Observational Specification no. 2013.1. Bureau of Meteorology, Department of the Environment, Sports and Territories, available at: www.bom.gov.au/inside/oeb/networks/ 20131.pdf

Cinner JE, McClanahan TR, Daw TM, Grahan NAJ, Maina J, Wilson SK, Hughes T (2009) Linking social and ecological systems to sustain coral reef fisheries. Curr Biol 19: 206-212

CSIRO and Australian Bureau of Meteorology (2007) Climate change in Australia. Technical Report 2007. CSIRO, Clayton, VIC

Davenport J (1989) Sea turtles and the greenhouse effect. Br Herpetol Soc Bull 29:11-15

> Davenport J (1997) Temperature and the life-history strategies of sea turtles. J Therm Biol 22:479-488

Dobbs KA, Miller JD, Limpus CJ, Landry AMJ (1999) Hawksbill turtle, Eretmochelys imbricata, nesting at Milman Island, northern Great Barrier Reef, Australia. Chelonian Conserv Biol 3:344-361

Glen F, Mrosovsky N (2004) Antigua revisited: the impact of climate change on sand and nest temperatures at a hawksbill turtle (Eretmochelys imbricata) nesting beach. Glob Change Biol 10:2036-2045

Godfrey MH, Barreto R, Mrosovsky N (1996) Estimating past and present sex ratios of sea turtles in Suriname. Can J Zool 74:267-277

Godley BJ, Broderick AC, Downie JR, Glen F and others (2001) Thermal conditions in nests of loggerhead turtles: further evidence suggesting female skewed sex ratios of hatchling production in the Mediterranean. J Exp Mar Biol Ecol 263:45-63

Hamann M, Limpus C, Read M (2007) Vulnerability of marine reptiles in the Great Barrier Reef to climate change. In: Johnson J, Marshall P (eds) Climate change and the Great Barrier Reef: a vulnerability assessment. Great Barrier Reef Marine Park Authority and Australian Greenhouse Office, Townsville, QLD, p 465-496

> Hawkes LA, Broderick AC, Godfrey MH, Godley BJ (2007) Investigating the potential impacts of climate change on a marine turtle population. Glob Change Biol 13:923-932

Hawkes LA, Broderick AC, Godfrey MH, Godley BJ (2009) Climate change and marine turtles. Endang Species Res $7: 137-154$ 
Hays GC, Godley BJ, Broderick AC (1999) Long-term thermal conditions on the nesting beaches of green turtles on Ascension Island. Mar Ecol Prog Ser 185:297-299

Hays GC, Ashworth JS, Barnsley MJ, Broderick AC and others (2001) The importance of sand albedo for the thermal conditions on sea turtle nesting beaches. Oikos 93: $87-94$

Hays GC, Broderick AC, Glen F, Godley BJ (2003) Climate change and sea turtles: a 150-year reconstruction of incubation temperatures at a major marine turtle rookery. Global Change Biol 9:642-646

Hurvish CM, Tsai C (1989) Regression and time series model selection in small samples. Biometrika 76:297-307

IPCC (2007) Climate change 2007: the physical science basis. Contribution of Working Group I to the Fourth Assessment Report of the Intergovernmental Panel on Climate Change (IPCC). Cambridge University Press, Cambridge

Janzen FJ (1994) Climate change and temperature-dependent sex determination in reptiles. Proc Natl Acad Sci USA 91:7487-7490

Johnson JB, Omland K (2004) Model selection in ecology and evolution. Trends Ecol Evol 19:101-108

Matsuzawa Y, Sato K, Sakamoto W, Bjorndal KA (2002) Seasonal fluctuations in sand temperature: effects on the incubation period and mortality of loggerhead sea turtle (Caretta caretta) pre-emergent hatchlings in Minabe, Japan. Mar Biol 140:639-646

Maynard JA, Turner PJ, Anthony KRN, Baird AH and others (2008) ReefTemp: an interactive monitoring system for coral bleaching using high-resolution SST and improved stress predictors. Geophys Res Lett 35:L05603

McClain CR, Hooker SB, Feldman GC, Bontempi P (2006) Satellite data for ocean biology, biogeochemistry, and climate research. EOS Trans Am Geophys Union 87

McMahon CR, Hays GC (2006) Thermal niche, large-scale movements and implications of climate change for a critically endangered marine vertebrate. Global Change Biol 12:1330-1338

Miller JD (1985) Embryology of marine turtles. In: Gans C, Billett F, Maderson PFA (eds) Biology of the Reptilia, Vol 14. Wiley Interscience, New York, p 271-328

Miller JD, Limpus CJ (1981) Incubation period and sexual differentiation in the green turtle Chelonia mydas. In: Banks CB, Martin A (eds) Proceedings of the Melbourne Herpetological Symposium. The Zoological Board of Victoria, Melbourne, VIC, p 66-73

Editorial responsibility: Mathew Godfrey, Beaufort, North Carolina, USA
Minnett PJ, Brown OB, Evans RH, Key EL and others (2004) Sea-surface temperature measurements from the Moderate-Resolution Imagine Spectroradiometer (MODIS) on Aqua and Terra. Proc Int Geosci Remote Sens Symp, 2-24 Sep 2004, Anchorage, AK. IEEE, Piscataway, NJ, p 4576-4579

> Mitchell NJ, Kearney MR, Nelson NJ, Porter WP (2008) Predicting the fate of a living fossil: How will global warming affect sex determination and hatching phenology in tuatara? Proc R Soc Lond B Biol Sci 275:2185-2193

> Morjan CL (2003) How rapidly can maternal behaviour affecting primary sex ratio evolve in a reptile with environmental sex determination? Am Nat 162:205-219

> Mrosovsky N, Pieau C (1991) Transitional range of temperature, pivotal temperatures and thermosensitive stages for sex determination in reptiles. Amphib-Reptil 12:169-179

Mrosovsky N (1994) Sex ratios of sea turtles. J Exp Biol 270: $16-27$

Mrosovsky N, Hopkinsmurphy SR, Richardson JI (1984) Sex ratio of sea turtles: seasonal changes. Science 225: 739-741

Naro-Maciel N, Mrosovsky N, Marcovaldi MA (1999) Thermal profiles of sea turtle hatcheries and nesting areas at Praia do Forte, Brazil. Chelonian Conserv Biol 3:407-413

> Packard GC, Tracy CR, Roth JJ (1977) The physiological ecology of reptilian eggs and embryos, and the evolution of viviparity within the class Reptilia. Biol Rev Camb Philos Soc 52:71-105

Pike DA, Antworth RL, Stinger JC (2006) Earlier nesting contributes to shorter nesting seasons for the loggerhead sea turtle, Caretta caretta. J Herpetol 40:91-94

Schwanz LE, Janzen FJ (2008) Climate change and temperature-dependent sex determination: Can individual plasticity in nesting phenology prevent extreme sex ratios? Physiol Biochem Zool 81:826-834

Spotila JR, Standora EA (1985) Environmental constraints on the thermal energetics of sea turtles. Copeia 1985: $694-702$

Spotila JR, Standora EA, Morreale SJ, Ruitz GJ (1987) Temperature dependent sex determination in green turtle (Chelonia mydas): effects on the sex ratio on a natural nesting beach. J Herpetol 43:74-81

Standora EA, Spotila JR (1985) Temperature dependent sex determination in sea turtles. Copeia 1985:711-722

- Weishampel JF, Bagley DA, Ehrhart LM (2004) Earlier nesting by loggerhead sea turtles following sea surface warming. Global Change Biol 10:1424-1427

Submitted: November 21, 2008; Accepted: July 25, 2009

Proofs received from author(s): November 5, 2009 